\title{
Waiting for repair: Neonatal risk for brain injury during the preoperative period
}

\author{
Ryan R. Davies, MD
}

\footnotetext{
From the Department of Cardiovascular and Thoracic Surgery, UT Southwestern Medical Center and Children's Health, Dallas, Tex.

Disclosures: Author has nothing to disclose with regard to commercial support.

Received for publication June 26, 2018; revisions received June 26, 2018; accepted for publication June 27, 2018; available ahead of print Aug 10, 2018.

Address for reprints: Ryan R. Davies, MD, Department of Cardiovascular and Thoracic Surgery, UT Southwestern Medical Center and Children's Health, 1935 Medical District Dr, MC B3.410, Dallas, TX (E-mail: ryan.davies@utsouthwestern.edu).

J Thorac Cardiovasc Surg 2018;156:1665-6

$0022-5223 / \$ 36.00$

Copyright (c) 2018 by The American Association for Thoracic Surgery

https://doi.org/10.1016/j.jtcvs.2018.06.062
}

During the 1970s, the initial push to move from staged palliative surgery to early neonatal correction was driven by several factors, including avoidance of the complications and mortality associated with the palliative procedure, minimization of the stress on a patient's family, and reversal of the failure to thrive associated with the interstage period. ${ }^{1}$ Since that time, single-stage operative repair of complex congenital heart defects has become standard at most institutions. However, the optimal timing of procedures within the neonatal period-especially in lesions resulting in hypoxia before surgical repair-remains uncertain.

The study by Lynch and colleagues ${ }^{2}$ adds to a growing body of literature identifying the potential pitfalls of delaying surgical intervention beyond the first few days. The authors use a noncommercial optical instrument to measure cerebral oximetry in neonates before repair of a variety of congenital heart defects. These measurements are combined with noninvasive bedside monitoring to estimate cerebral blood flow and oxygen consumption.

The study has 2 primary findings: cerebral oxygen saturation (an estimate of jugular venous saturation) decreases between birth and surgery, and blood flow index (an estimate of cerebral blood flow) is unchanged (or shows a trend toward a decrease). The result is an increase in the calculated oxygen extraction fraction during the postnatal period. Whatever the underlying mechanisms of this change (potential contributors include alterations in effective Qp:Qs over time and the fall in hemoglobin during the preoperative period), this does suggest that cerebral autoregulation may not be functioning normally to maintain normal cerebral oxygen delivery. This is in notable contrast to the decrease in cerebrovascular resistance identified in utero. As the authors note, the underlying mechanism appears to be an inability to further decrease cerebrovascular resistance to and increase cerebral blood flow.

It is possible that these factors result in an increased risk for brain injury and contribute to neurodevelopmental challenges faced by children with congenital heart disease,

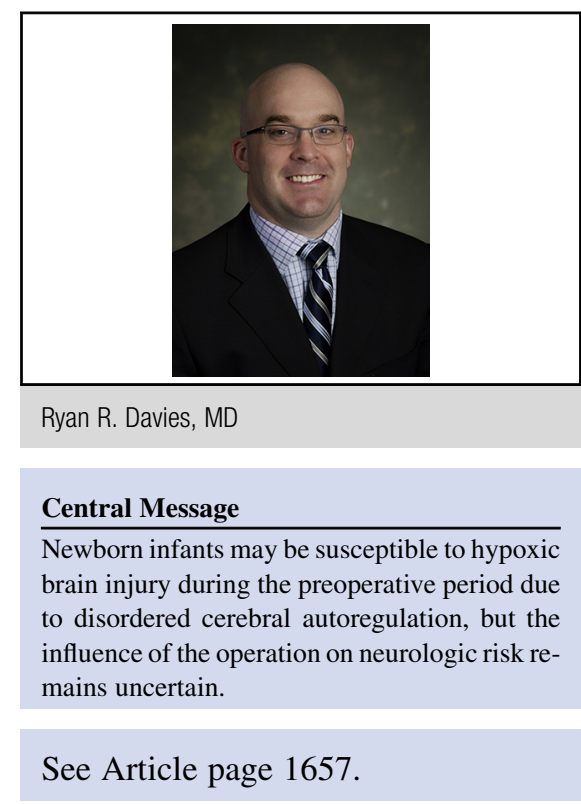

but the link remains speculative. Furthermore, the normal pattern of cerebral oxygen extraction and cerebral blood flow in the face of progressive anemia as seen in these hospitalized, critically ill patients is not known. Whether surgical repair alters this risk is similarly uncertain. Although an arterial switch operation would normalize systemic oxygen saturations and improve cerebral oxygen delivery, the same is not true of performing a stage 1 palliation for hypoplastic left heart syndrome.

Prior work from the same group has suggested that children with longer periods between birth and surgery (and lower oxygen tension) were at increased risk of preoperative white matter injury. ${ }^{3}$ However, this study evaluated only patients during the preoperative phase; whether the evolution or risk for brain injury was altered by surgery remains uncertain. In fact, the alterations in cerebral perfusion and hemodynamic parameters may contribute to further brain injury ${ }^{4}$; how brain maturation alters this risk is not addressed in the current study.

This study further demonstrates the complex interactions between congenital heart disease, perioperative management, and the risk for neurologic injury and neurodevelopmental delay. As a practical matter, the lack of cerebral autoregulation suggests that an increased focus on maintaining oxygen delivery during the postnatal period (including minimizing blood draws and maximizing hemoglobin) may be important for improving outcomes. 
Moving forward, a better understanding of how cardiopulmonary bypass interacts with the risk of brain injury is necessary to optimize the timing of these complex procedures during neonatal life.

\section{References}

1. Castaneda AR, Lamberti J, Sade RM, Williams RG, Nadas AS. Open-heart surgery during the first three months of life. J Thorac Cardiovasc Surg. 1974; 68:719-31.
2. Lynch JM, Ko T, Busch DR, Newland JJ, Winters ME, Mensah-Brown K, et al. Preoperative cerebral hemodynamics from birth to surgery in neonates with critical congenital heart disease. J Thorac Cardiovasc Surg. 2018;156:1657-64.

3. Preoperative brain injury in transposition of the great arteries is associated with oxygenation and time to surgery, not balloon atrial septostomy. Circulation. 2009;119:709-16.

4. Andropoulos DB, Hunter JV, Nelson DP, Stayer SA, Stark AR, McKenzie ED, et al. Brain immaturity is associated with brain injury before and after neonatal cardiac surgery with high-flow bypass and cerebral oxygenation monitoring. J Thorac Cardiovasc Surg. 2010;139:543-56. 